(c) American Dairy Science Association, 2004.

\title{
Release of Short and Proline-Rich Antihypertensive Peptides from Casein Hydrolysate with an Aspergillus oryzae Protease
}

\author{
S. Mizuno, S. Nishimura, K. Matsuura, T. Gotou, and N. Yamamoto \\ R\&D Center, Calpis Co., Ltd., 11-10, 5-Chome, \\ Fuchinobe, Sagamihara, Kanagawa 229-0006, Japan
}

\begin{abstract}
Angiotensin-I converting enzyme inhibitory activities were measured after hydrolysis of casein by 9 different commercially available proteolytic enzymes. Among these enzymes, a protease isolated from Aspergillus ory$z a e$ showed the highest angiotensin-I converting enzyme inhibitory activity per peptide. The $A$. oryzae peptide also showed the highest antihypertensive effect in spontaneously hypertensive rats when the systolic blood pressure was measured $5 \mathrm{~h}$ after oral administration of $32 \mathrm{mg} / \mathrm{kg}$ of various enzymatic hydrolysates. Significant antihypertensive effects were observed with dosages of $9.6,32$, and $96 \mathrm{mg}$ of the A. oryzae peptide/ $\mathrm{kg}$ of body weight (BW), and the effects were dependent on these peptide dosages.

Analysis of peptide length showed the A. oryzae hydrolysate was the shortest of all tested casein hydrolysates; the peptide mixture had an average value of 1.4 amino acids (AA) in the sequence. To further characterize the $A$. oryzae hydrolysate, we analyzed the AA sequence of the whole peptide mixture. Various AA were detected at the first AA position, however, an increased number of Pro residues were observed at the second and third position of the A. oryzae hydrolysate. No strong signals were detected after the fourth AA position of the $A$. oryzae hydrolysate. These results suggest that the casein hydrolysate of $A$. oryzae, which expressed potent antihypertensive effects in spontaneously hypertensive rats, mainly contain short peptides of X-Pro and $\mathrm{X}$-Pro-Pro sequences.
\end{abstract}

(Key words: antihypertensive peptide, angiotensin-I converting enzyme, Aspergillus oryzae protease, casein hydrolysate)

Abbreviation key: ACE = angiotensin-I converting enzyme, FOSHU = Food for Specified Health Use, $\mathbf{S B P}=$ systolic blood pressure, $\mathbf{S H R}=$ spontaneously hypertensive rats.

Received February 2, 2004.

Accepted May 31, 2004

Corresponding author: N. Yamamoto; e-mail: naoyuki.yamamoto @calpis.co.jp.

\section{INTRODUCTION}

Various physiologically functional peptides (bioactive peptides), such as opioid peptides (Teschemacher et al., 1997), antibacterial peptides (Lahov and Regelson, 1996), immunostimulating peptides (Lahov and Regelson, 1996), antioxidant peptides (Kim et al., 2001), and angiotensin-I converting enzyme (kininase II; EC 3.4.15.1)(ACE) inhibitory peptides, have been reported from protein hydrolysates, synthetic peptides, and fermented products and have been reviewed (Meisel and Bockelmann, 1999; Yamamoto et al., 2003). In the enzymatic preparation of bioactive peptides, casein is an appropriate protein source because of its safety and its long history in the human diet. It also has potential for easy processing because of the flexible and open structure. Various kinds of protease, such as trypsin, proteinase $\mathrm{K}$, and thermolysin, have been used in the enzymatic hydrolysis of casein (Maruyama et al., 1985; Miyoshi et al., 1991; Yokoyama et al., 1992; Matsumura et al., 1993). Antihypertensive peptides have been studied extensively to determine biologically functional peptides; techniques include in vitro ACE inhibitory activity and in vivo studies using spontaneously hypertensive rats (SHR).

In our study, 2 kinds of ACE inhibitory peptides, ValPro-Pro and Ile-Pro-Pro, were generated from $\beta$ - and $\gamma$ $\mathrm{CN}$ isolated from milk fermented with Lactobacillus helveticus (Nakamura et al., 1995a, b). The L. helveticus-fermented milk and peptide materials isolated from the fermented milk, which contained Val-Pro-Pro and Ile-Pro-Pro, showed antihypertensive effects in Japanese and Finish hypertensive subjects (Hata et al., 1996; Seppo et al., 2002). Generally, most of the reported ACE inhibitory peptides are short peptides with a Pro residue at the carboxyl terminal end (Yamamoto et al., 2003). The Pro residue at the $\mathrm{C}$-terminus seems to have an important structural function in expressing strong inhibitory activity against ACE. Moreover, a short peptide is more readily absorbed from the gastrointestinal tract.

In this study, we prepared antihypertensive peptides from various commercially available proteases and studied their activity. 
Table 1. Comparison of angiotensin-I converting enzyme (ACE) inhibitory activities and antihypertensive effects of various enzymatic casein hydrolysates.

\begin{tabular}{|c|c|c|c|}
\hline Protease & Origin & $\begin{array}{l}\text { ACE } \\
\text { inhibitory } \\
\text { activity }\end{array}$ & $\begin{array}{l}\text { Decrease } \\
\text { in } \mathrm{SBP}^{1}\end{array}$ \\
\hline & & $(\% / \mu \mathrm{g})$ & $-(\mathrm{mm} \mathrm{Hg})-$ \\
\hline & & & $\overline{\mathrm{X}} \quad \mathrm{SD}$ \\
\hline Sumizyme FP & Aspergillus oryzae & 4.1 & $-25.0 \pm 4.3^{* * *}$ \\
\hline Trypsin & Porcine pancreas & 0.8 & $-4.3 \pm 5.3$ \\
\hline Sumizyme CP & Bacillus subtilis & 1.2 & Not tested \\
\hline Protease S & Bacillus stearothermophilus & 1.4 & $-3.7 \pm 6.4$ \\
\hline Papain & Carica papaya & 1.0 & $2.8 \pm 5.2$ \\
\hline Thermoase & Bacillus stearothermophilus & 1.1 & Not tested \\
\hline Neurase F3G & Rhizopus nivenus & 0.9 & $2.9 \pm 5.4$ \\
\hline Sumizyme RP & Rhizopus delemar & 0.7 & $-5.1 \pm 7.0$ \\
\hline Bromeraine & Pineapple cannery & 1.1 & $-4.6 \pm 6.9$ \\
\hline Not used (control) & & Not tested & $-2.5 \pm 7.5$ \\
\hline
\end{tabular}

${ }^{1}$ Mean of changes in systolic blood pressure at $5 \mathrm{~h}$ after an oral administration to spontaneously hypertensive rats $(\mathrm{n}=5)$.

*** Significant difference from the control $(\mathrm{P}<0.001)$.

\section{MATERIALS AND METHODS}

\section{Materials}

Hippuryl-Histidyl-Leucine (Hip-His-Leu) and ACE from rabbit lung and casein were purchased from Sigma Aldrich Japan (Tokyo, Japan). Proteases, such as Sumizyme FP, Sumizyme CP, and Sumizyme RP, were purchased from Shinnihon Chemical Company (Anjyou, Japan). Trypsin, protease S, neurase F3G, thermoase, and bromeraine were obtained from Amano Enzyme Inc. (Nagoya, Japan). Trypsin was purchased from Higuchi Inc. (Tokyo, Japan), and papain was obtained from Nagase Chemtex Corporation (Kyoto, Japan). Casein was purchased from Takanashi (Hokkaidou, Japan). $O$-phthalaldehyde was obtained from Wako Pure Chemical Industries, Ltd. (Osaka, Japan)

\section{Preparation of the Casein Hydrolysate}

Casein was dissolved in hot water $\left(80^{\circ} \mathrm{C}\right)$ to $15 \%$ (wt/ vol), and the $\mathrm{pH}$ was adjusted to 7.0 by the addition of $1 \mathrm{~N} \mathrm{NaOH}$. After cooling to $<20^{\circ} \mathrm{C}$, various enzymes, listed in Table 1, were added directly to the casein solution at a final concentration of $0.6 \%$ (wt/vol). Each reaction mixture was incubated at $50^{\circ} \mathrm{C}$ for 14 and 24 $\mathrm{h}$, after which the reaction was stopped by heating to $110^{\circ} \mathrm{C}$ for $10 \mathrm{~min}$. The antihypertensive effect of each casein hydrolysate was measured by the method described subsequently. To characterize the peptides in the casein hydrolysates, nonhydrolysed protein and AA were removed by trapping the peptides in a tC18 Seppak cartridge (Waters, MA). The cartridge was washed with $10 \mathrm{~mL}$ of water, and peptides in the cartridge were eluted with $5 \mathrm{~mL}$ of $50 \%$ (wt/vol) ethanol. The eluted peptides were lyophilized and dissolved in Tris-Cl $(\mathrm{pH}$ 8.0) for analysis of the ACE activity and peptide length.

\section{Measurement of ACE Inhibitory Activity}

The ACE inhibitory activity was measured according to the method of Cushman and Cheung (1971), with modification (Nakamura et al., 1995a). Twenty microliters of peptide solution were preincubated with HipHis-Leu borate buffer (3.8 $\mathrm{m} M$ Hip-His-Leu, $0.1 M$ borate, and $0.3 \mathrm{M} \mathrm{NaCl} ; \mathrm{pH} 8.3$ ) at $37^{\circ} \mathrm{C}$ for $5 \mathrm{~min}$. Two milliunits of ACE were then added, and the mixture was incubated at $37^{\circ} \mathrm{C}$ for $30 \mathrm{~min}$. The liberated hippuric acid was extracted with ethyl acetate. The activity of an ACE inhibitory peptide was defined as the amount needed to inhibit $50 \%$ of the ACE activity under these conditions.

\section{Measurement of Blood Pressure}

Male SHR, purchased from Charles River Japan (Yokohama, Japan), were divided into groups with each containing 5 rats fed laboratory chow (CE-2; Clea Japan, Tokyo, Japan). Systolic blood pressure (SBP) of the SHR at 21 to 23 wk old (BW, 310 to $330 \mathrm{~g}$ ) was measured as follows. All rats were incubated at $45^{\circ} \mathrm{C}$ for $5 \mathrm{~min}$, and the SBP was measured at the tail cuff with a programmed electro-sphygmomanometer (NARCO Bio-Systems, Austin, TX). Casein hydrolysates prepared by various proteases were orally administered by gastric intubation with nonhydrolysed casein as a control. Student's $t$-test was used for statistical analysis. 


\section{Evaluation of Peptide Length}

The amount of $\mathrm{N}$-terminal AA of the peptides isolated from the tC18 Sep-pak cartridge was measured by the $o$-phthalaldehyde method described previously, using casamino acid (Difco Co. Ltd., Detroit, MI) as a control. Casamino acid is an AA mixture with the same AA composition as casein because it is a casein hydrolysate with $\mathrm{HCl}$. To evaluate the average peptide length, the number of $\mathrm{N}$-terminal $\mathrm{AA}$ of each casein hydrolysate was measured, and the value was compared with the value for casamino acid. Average peptide length was calculated as follows: average peptide length = the number of N-terminal AA for casamino acid/the number of $\mathrm{N}$-terminal AA for each casein hydrolysate.

\section{AA Sequence Analysis}

To characterize the enzymatic peptide hydrolysate, the AA sequence of the peptide mixture, prepared by a Sep-pak cartridge, was determined by a protein sequencer PPSQ-10 (Shimadzu, Japan).

\section{Results}

\section{Selection of the Enzyme}

To select potent ACE inhibitory peptides, various casein hydrolysates were prepared, as described in Materials and Methods, using 9 different commercially available proteolytic enzymes. The percentage of inhibitory ACE activity for $1 \mu \mathrm{g}$ of peptide was measured using the method described in Materials and Methods, and it is shown in Table 1. The ACE inhibitory activities were detected in all peptide samples listed in Table 1. However, among these enzymatic casein hydrolysates, a peptide with sumizyme FP, the protease from Aspergillus oryzae, showed the highest ACE inhibitory activity per peptide (Table 1). All results shown in Table 1 were obtained with hydrolysate when the enzyme reaction was stopped at $14 \mathrm{~h}$; if enzyme reactions were prolonged to $24 \mathrm{~h}$, there was little difference between the inhibitory activities (data not shown). During the enzyme reaction, precipitation was observed in all hydrolysates, but the amount of precipitate was lowest in the $A$. oryzae hydrolysate.

To compare the in vivo effects of selected casein hydrolysates listed in Table 1, the SBP of SHR was measured by a tail-cuff method, $5 \mathrm{~h}$ after oral administration of $32 \mathrm{mg}$ of hydrolysate/kg of BW. As shown in Table 1 , the casein hydrolysate from the $A$. oryzae protease (sumizyme FP) showed the highest activity in blood pressure, lowering among all 8 samples tested. The SBP of the SHR decreased by $25.0 \mathrm{~mm} \mathrm{Hg}$ after oral administration of the $A$. oryzae peptide, compared with
Dosage of casein hydrolysate to SHR ( $\mathrm{mg} / \mathrm{kg}$ of BW)

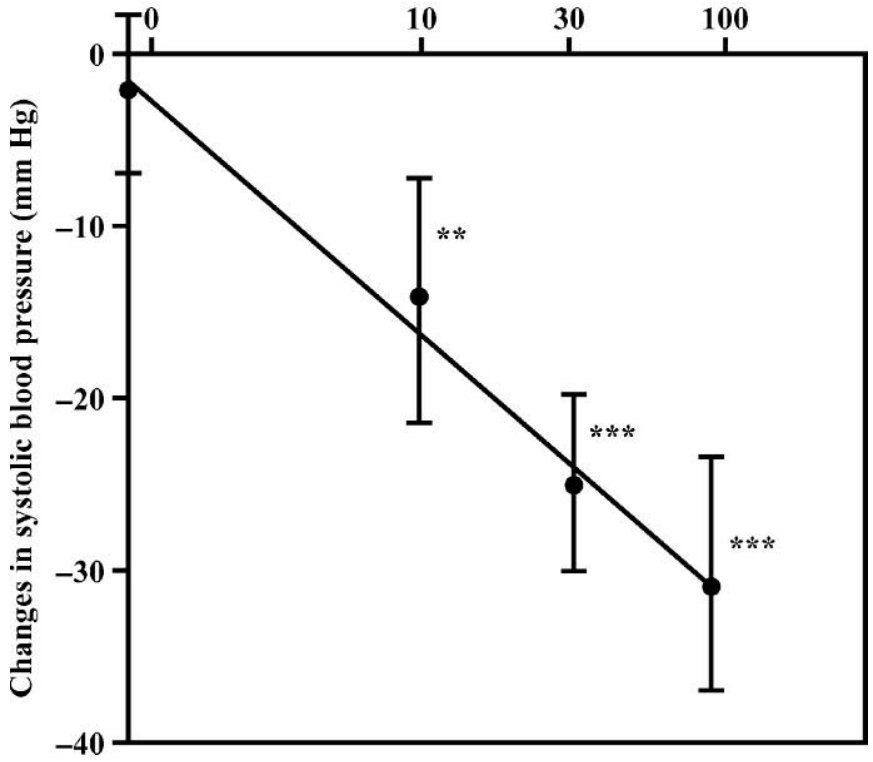

Figure 1. Antihypertensive effect of different dosages of casein hydrolysate with Aspergillus oryzae protease, from 9.6 to $96 \mathrm{mg} / \mathrm{kg}$ of BW. Vertical bars represent standard error $(n=5)$. Asterisks indicate the level of significant difference from the control: $* * P<0.01$ and $* * * P<0.001$

$2.5 \mathrm{~mm} \mathrm{Hg}$ after oral administration of the control (casein). The antihypertensive effect of the A. oryzae peptide on the SHR was significant when compared with the control group $(P<0.001)$. There was high correlation between in vitro ACE inhibitory activity and in vivo blood pressure lowering activity for the tested samples, which suggests that the $A$. oryzae hydrolysate has a potential use as a blood pressure-lowering material. From these results, the $A$. oryzae hydrolysate showed the highest antihypertensive activity and was selected for further analysis.

\section{Dose-Dependent Effect of the A. oryzae Peptide on Blood Pressure}

The dose dependent effect of the A. oryzae peptide on SHR was examined. Significant antihypertensive effects of the A. oryzae peptide were observed at dosages between 9.6 and $96 \mathrm{mg} / \mathrm{kg}$ of BW. The changes in SBP at $9.6,32$, and $96 \mathrm{mg}$ were $-14.4 \mathrm{~mm} \mathrm{Hg}(P<0.01)$, $-25.1 \mathrm{~mm} \mathrm{Hg}(P<0.001)$, and $-31.0 \mathrm{~mm} \mathrm{Hg}(P<0.001)$, respectively, as shown in Figure 1. Moreover, a dosedependent antihypertensive effect of the A. oryzae peptide was observed with dosages between 9.6 and $96 \mathrm{mg} /$ $\mathrm{kg}$ of BW of SHR, and the effects were dependent on these peptide dosages (Figure 1). 


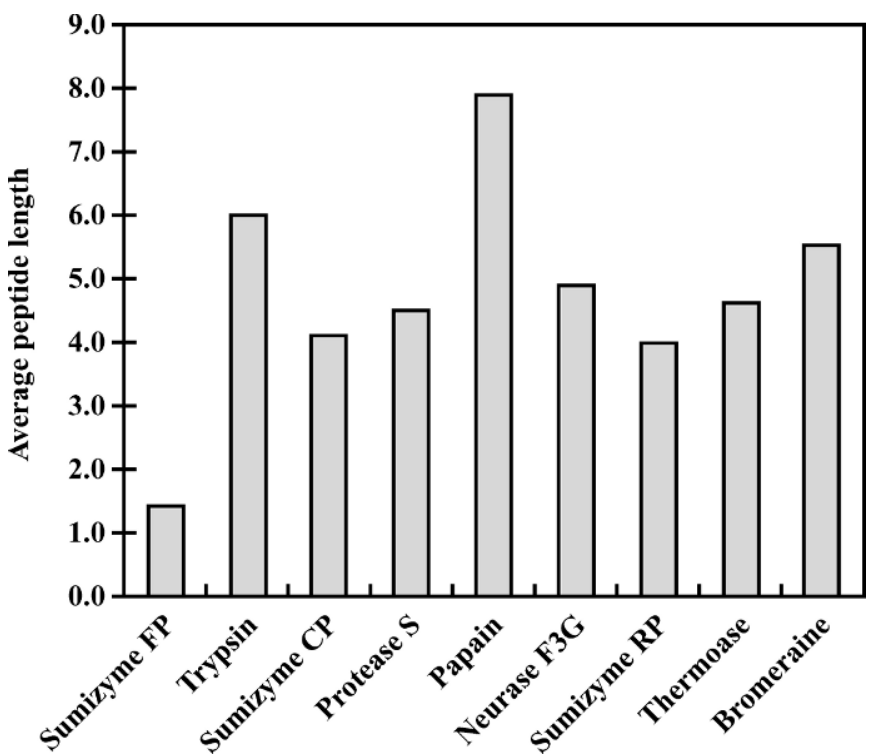

Figure 2. Average peptide lengths of the casein hydrolysates after treatment with various proteases. The number of amino group of each casein hydrolysate was measured by the $o$-phthalaldehyde method described in Materials and Methods, using casamino acid as a control.

\section{Characteristics of the A. oryzae Peptide}

To further understand the in vitro and in vivo activities of the A. oryzae peptide among the other casein hydrolysates, the number of $\mathrm{N}$-terminal ends of all samples was calculated by the $o$-phthalaldehyde method (Church et al., 1985), as described in Materials and Methods. Casein $\mathrm{HCl}$ hydrolysate was used as a control to evaluate average peptide length. As shown in Figure 2 , the average peptide length of the $A$. oryzae peptide was 1.4, which was the shortest of all tested samples; most of the other peptides had $>4.0 \mathrm{AA}$ as the peptide length. We suggest that peptide length may be an important factor in ACE inhibition and antihypertensive activity.

\section{AA Sequence}

The amino terminal AA of the A. oryzae peptide mixture was analyzed to help understand its structure. Various AA residues were observed at the first amino terminal end of the peptide mixture. Interestingly, a Pro residue was mainly detected at the second and third AA position (Table 2). No strong signal was detected at the fourth, fifth, and sixth AA position. The number of AA released was calculated and is shown in Table 2. Amino acid signal released from the amino terminal end decreased gradually at the second and third AA positions; signals after the fourth AA position decreased to a basal level (Table 2). From these results, we suggest that a high amount of di- and tripeptide in the A. oryzae hydrolysate exists. These findings support the results of the average peptide length listed in Table 1. Our results strongly suggest that the $A$. oryzae peptides contain mostly di- and tripeptides of X-Pro and X-ProPro sequences.

\section{DISCUSSION}

In this study, casein hydrolysate prepared by A. oryzae showed a potent in vitro ACE inhibitory activity and in vivo blood pressure-lowering effect compared with other casein hydrolysates. From AA sequence analysis of the A. oryzae hydrolysate, the existence of short peptides of X-Pro-Pro and X-Pro peptides was suggested. These X-Pro-Pro and X-Pro peptides may be generated from excess proteolytic reactions catalyzed by a strong $A$. oryzae protease because there was a high content of AA in the hydrolysate (data not shown). Therefore, peptides remaining in the hydrolysate should have a high resistance to proteolytic enzyme action because the $A$. oryzae protease contains potent proteolytic enzyme activities.

Many reported ACE inhibitory peptides have a Pro residue at the C-terminal end (Nakamura et al., 1995a; Yamamoto et al., 1999). Short peptides containing Pro residues at the C-terminus are thought to be an appropriate ACE inhibitory peptide material. Recently, some kinds of antihypertensive peptides that had ACE inhibitory activities were isolated from some traditional cheese and proteolytic digests of whey proteins by HPLC (Abubakar et al., 1998; Saito et al., 2000). In that study, most of peptides purified from the whey protein hydrolysate prepared with a proteinase K treatment also contained Pro at the C-terminal end (Saito et al., 2000). The trypsin hydrolysate of whey protein showed a significant antihypertensive effect on SHR at $6 \mathrm{~h}$ after administration with a dosage of $8 \mathrm{mg} / \mathrm{kg}$ of BW (Saito et al., 2000). However, trypsin did not generate antihypertensive peptides from casein in this study, indicating the importance of the combination of protease and substrate protein to release active antihypertensive peptides.

Many kinds of ACE inhibitory peptides have been reported, however, pharmacokinetical studies of these peptides in SHR have not been comprehensively analyzed. In previous studies, the antihypertensive peptides, Val-Pro-Pro and Ile-Pro-Pro, showed potent blood pressure-lowering effects in animal (Nakamura et al., 1995b) and clinical studies (Hata et al., 1996). Moreover, the peptides were detected in a target organ, the aorta, in SHR after oral administration of these peptides (Kodama et al., 2002). Therefore, resistance of the ACE inhibitory peptide to proteolytic enzymes in vivo 
Table 1. Number of released AA from the N-terminus of casein hydrolysate by an Aspergillus oryzae protease

\begin{tabular}{|c|c|c|c|c|c|c|}
\hline \multirow[b]{2}{*}{ AA } & \multicolumn{6}{|c|}{ Position of N-terminus } \\
\hline & 1st & 2nd & 3rd & 4 th & 5 th & 6 th \\
\hline & & & & & & $(\mathrm{pmol})$ \\
\hline Asp & 82 & 304 & 115 & 63 & 45 & 32 \\
\hline Glu & 139 & 127 & 89 & 121 & 75 & 53 \\
\hline Asn & 55 & 49 & 46 & 91 & 43 & 35 \\
\hline Gln & 80 & 97 & 104 & 80 & 72 & 65 \\
\hline Ser & 105 & 36 & 27 & 16 & 11 & 23 \\
\hline Thr & 31 & 16 & 25 & 18 & 12 & 23 \\
\hline His & 28 & 94 & 58 & 0 & 3 & 3 \\
\hline Gly & 256 & 38 & 33 & 16 & 5 & 6 \\
\hline Ala & 323 & 101 & 58 & 30 & 22 & 11 \\
\hline Tyr & 725 & 114 & 52 & 28 & 19 & 23 \\
\hline Arg & 13 & 7 & 6 & 8 & 7 & 12 \\
\hline Met & 182 & 43 & 36 & 10 & 5 & 7 \\
\hline Val & 869 & 127 & 196 & 64 & 42 & 22 \\
\hline Pro & 42 & 1371 & 431 & 186 & 102 & 83 \\
\hline $\operatorname{Trp}$ & 94 & 46 & 26 & 6 & 2 & 4 \\
\hline Phe & 800 & 88 & 60 & 28 & 23 & 19 \\
\hline Lys & 81 & 33 & 57 & 19 & 11 & 9 \\
\hline Ile & 350 & 37 & 17 & 10 & 6 & 8 \\
\hline Leu & 400 & 39 & 50 & 10 & 7 & 12 \\
\hline Total & 4317 & 2767 & 1447 & 805 & 512 & 450 \\
\hline
\end{tabular}

seems to be a very important characteristic in expressing a potent antihypertensive effect in SHR. Peptides having X-Pro-Pro and X-Pro sequences most likely exist in $A$. oryzae and may show resistance to proteolysis in SHR, especially after reaching the target organ. It has been suggested that strong in vitro ACE inhibitory activity and antihypertensive activity in SHR might be due to Pro-rich peptides. We suggest that the A. oryzae protease might be a suitable enzyme to generate potent ACE inhibitory activity and antihypertensive activity. To further understand the in vitro and in vivo activities, identification of each active component and confirmation of the Pro-rich sequence in the hydrolysate is essential. We attempted to isolate all peptides in the A. oryzae hydrolysate by HPLC; however, short peptides were eluted in such a narrow range that it was difficult to isolate each individual peptide. We suggest that the liquid chromatography-mass spectrometry method would be a useful tool in the quantification of X-ProPro and X-Pro peptides in hydrolysate.

Aspergillus oryzae has a long history in the manufacturing of fermented food products in Japan, for example, rice wine, soy sauce, miso, and some traditional fermented food products (Masuda et al., 1996; O'Toole, 1999; Chiou and Cheng, 2001). Aspergillus oryzae plays an important role in accelerating ripening during fermentation because of rapid growth in protein sources caused by strong proteolytic activity and sugar utility. Casein and proteolytic enzymes of $A$. oryzae are well known as safe food materials. Therefore, it is likely that other A. oryzae peptides will also be safe as food products. Moreover, a recent toxicity study in rodents and an antigenicity study proved the $A$. oryzae hydrolysate to be a safe food product (data not shown).

In Japan, regulation for functional food was established in 1991 as FOSHU (Food for Specified Health Use). To date, almost 400 kinds of FOSHU products are registered in Japan, and the market of FOSHU products is still expanding. For the application of this peptide material as a FOSHU product, a clinical study concerned with safety and efficacy would be necessary. Antihypertensive peptides prepared by casein hydrolysis with the A. oryzae protease used in this study might have potential for use in various types of food products as functional peptide materials.

\section{REFERENCES}

Abubakar, A., T. Saito, H. Kitazawa, Y. Kawai, and T. Itoh. 1998. Structural analysis of new antihypertensive peptides derived from cheese whey protein by proteinase K digestion. J. Dairy Sci. 81:3131-3138.

Chiou, R. Y., and S. L. Cheng. 2001. Isoflavone transformation during soybean koji preparation and subsequent miso fermentation supplemented with ethanol and NaCl. J. Agric. Food Chem. 49:3656-3660.

Church, F. C., D. H. Porter, G. L. Catignani, and H. Swaisgood. 1985. An $o$-phthalaldehyde spectrophotometric assay for proteinases. Anal. Biochem. 146:343-348.

Cushman, D. W., and H. S. Cheung. 1971. Spectrophotometric assay and properties of angiotensin-converting enzyme of rabbit lung. Biochem. Pharmacol. 20:1637-1648.

Hata, Y., M. Yamamoto, M. Ohni, K. Nakajima, Y. Nakamura, and T. Takano. 1996. A placebo-controlled study of the effect of sour milk on blood pressure in hypertensive subjects. Am. J. Clin. Nutr. 64:767-771.

Kim, S. K., Y. T. Kim, H. G. Byun, K. S. Nam, D. S. Joo, and F, Shahide. 2001. Isolation and characterization of antioxidative peptides from gelatin hydrolyzate of Alaska pollack skin. J. Agric. Food Chem. 49:1984-1989. 
Kodama, S., A. Yamamoto, A. Matsunaga, K. Nakagomi, and K. Hayakawa. 2002. Behaviors of D- and L-lactic acids during the brewing process of sake (Japanese rice wine). J. Agric. Food Chem. 50:767-770

Lahov, E., and E. Regelson. 1996. Antibacterial and immunostimulating casein-derived substances from milk: Casecidin, isracidin peptides. Food Chem. Toxicol. 34:131-145.

Maruyama, S., K. Nakagomi, N. Tomizuka, and H. Suzuki. 1985. Angioten I-converting enzyme inhibitor derived from an enzymatic hydrolysate of casein. II. Isolation and bradykinin-potentiating activity on the uterus and the ileum of rats. Agric. Biol. Chem. 49:1405-1409.

Masuda, O., Y. Nakamura, and T. Takano. 1996. Antihypertensive peptides are present in aorta after oral administration of sour milk containing these peptides to spontaneously hypertensive rats. J. Nutr. 126:3063-3068.

Matsumura, N., M. Fujii, Y. Takeda, K. Sugita, and T. Shimizu. 1993. Angiotensin I-converting enzyme inhibitory peptides derived from bonito bowels autolysate. Biosci. Biotechnol. Biochem. 57:695-697.

Meisel, H., and W. Bockelmann. 1999. Bioactive peptides encrypted in milk proteins: Proteolytic activation and tropho-functional properties. Antonie van Leeuwenhoek 76:207-215.

Miyoshi, S., H. Ishikawa, T. Kaneko, F. Fukui, H. Tanaka, and S. Maruyama. 1991. Structures and activity of angiotensin-converting enzyme inhibitors in an alpha-zein hydrolysate. Agric. Biol. Chem. 55:1313-1318.
Nakamura, Y., N. Yamamoto, K. Sakai, A. Okubo, S. Yamazaki, and T. Takano. 1995a. Purification and characterization of angiotensin I-converting enzyme inhibitors from sour milk. J. Dairy Sci. 78:777-783

Nakamura, Y., N. Yamamoto, K. Sakai, and T. Takano. 1995b. Antihypertensive effect of sour milk and peptides isolated from it that are inhibitors to angiotensin I-converting enzyme. J. Dairy Sci. $78: 1253-1257$.

O'Toole, D. K. 1999. Characteristics and use of okara, the soybean residue from soy milk production. J. Agric. Food Chem. 47:363-371.

Saito, T., T. Nakamura, H. Kitazawa, Y. Kawai, and T. Itoh. 2000. Isolation and structural analysis of antihypertensive peptides that exist naturally in Gouda cheese. J. Dairy Sci. 83:1434-1440.

Seppo, L., O. Kerojoki, T. Suomalainen, and R. Korpela. 2002. The effect of a Lactobacillus helveticus LBK-16 $\mathrm{H}$ fermented milk on hypertension-A pilot study on humans. Milchwissenschaft 57:124-127.

Teschemacher, H., G. Kock, and V. Brantl. 1997. Milk protein-derived opioid receptor ligands. Biopolymers 43:99-117.

Yamamoto, N., M. Ejiri, and S. Mizuno. 2003 Biogenic peptides and their potential use. Curr. Pharm. Des. 9:1345-1355.

Yamamoto, N., M. Maeno, and T. Takano. 1999. Purification and characterization of an antihypertensive peptide derived from a yogurt-like product fermented by Lactobacillus helveticus CPN4. J. Dairy Sci. 82:1388-1393.

Yokoyama, K., H. Chiba, and M. Yoshikawa. 1992. Peptide inhibitors for angiotensin I-converting enzyme from thermolysin digest of dried bonito. Biosci. Biotechnol. Biochem. 56:1541-1945. 